Revista InterteXto / ISSN: 1981-0601

v. 10, n. 2 (2017)

\title{
DO CONFLITO À OCULTAÇÃO: UMA ANÁLISE DISCURSIVA DOS ENUNCIADOS MIDIÁTICOS EM TORNO DOS ÍNDIOS
}

\author{
FROM CONFLICT TO HIDING: A MEDIA'S DISCOURSIVE ANALYSIS ABOUT \\ BRAZILIAN INDIANS
}

Camilla Rodrigues Netto da Costa Rocha ${ }^{1}$

\begin{abstract}
Resumo: A atual conjuntura política e social do Brasil referente aos índios nos convoca ao exame de sua realidade. Partindo da centralidade da comunicação como mediadora de representações sociais sobre minorias representativas, selecionamos duas matérias jornalísticas veiculadas nos periódicos Nexo e Portal Globo (G1) e propomos refletir, no presente artigo, quais os sentidos articulados em torno dos índios, quando de sua manifestação na Esplanada dos Ministérios, Brasília, Brasil. Assim, tanto nos valemos metodologicamente como também propomos uma reflexão teórica acerca da Análise de Discurso de Linha Francesa (ADF), a partir de Orlandi, Baccega, Gregolin, entre outros. E ainda, para corroborar nossa investigação, trazemos reflexões pertinentes à linguagem com Bakhtin, Schaff, Baccega e aos enunciados midiáticos a partir de Baccega, Escosteguy, Canclini, Kellner e Gregolin.

Palavras-chave: Comunicação; Mídia; Linguagem; Análise de Discurso de Linha Francesa; Índios.
\end{abstract}

\begin{abstract}
The current political and social Brazil's conjuncture concerning the Indians, summons us to the examination of their reality. Based on the centrality of communication as a mediator of social representations about representative minorities, we selected two journalistic articles published in the periodicals Nexo and Portal Globo (G1) and propose to reflect, in this article, about the meanings articulated around the Indians by the press, taking into consideration their manifestation in the Esplanada dos Ministérios, Brasília, Brazil. Thus, we value both methodologically and also propose a theoretical reflection on the French Line Discourse Analysis (ADF), from authors like Orlandi, Baccega, Gregolin, among others. Also, to corroborate our investigation, we bring pertinent reflections about language with Bakhtin, Schaff, Baccega and about the mediatic statements with Baccega, Escosteguy, Canclini, Kellner and Gregolin.

Keywords: Communication; Media; Language; French Line Discourse Analysis (ADF); Indians.
\end{abstract}

\section{INTRODUÇÃO}

\footnotetext{
${ }^{1}$ Doutoranda no Programa de Pós-Graduação em Comunicação e Práticas de Consumo (PPGCOM/ESPM) da Escola Superior de Propaganda e Marketing (2017/2020), na qualidade de bolsista CAPES, modalidade PROSUP Integral. Mestre em Comunicação e Práticas de Consumo pelo PPGCOM/ESPM (2015/2017), com bolsa CAPES Prosup Integral. Integrante do grupo de pesquisa do $\mathrm{CNPq}$ denominado Comunicação, educação e consumo: as interfaces na teleficção, coordenado pela professora Dra. Maria Aparecida Baccega. Participante da rede OBITEL Brasil (Observatório Ibero-Americano de Fiç̧ão Televisiva), na equipe do PPGCOM/ESPM. Contato: camilla@,costarocha.com.br
} 


\section{Revista InterteXto / ISSN: 1981-0601 \\ v. 10, n. 2 (2017)}

Em todo contexto - local, regional ou global - quaisquer questões advindas das searas social e/ou política ganham visibilidade a partir do momento em que passam a ter presença na mídia. É assim que os meios de comunicação se destacam na contemporaneidade enquanto uma agência de socialização das mais importantes. Deste modo, ao se pretender compreender quaisquer dos acontecimentos que têm lugar na sociedade, torna-se relevante examinar os discursos midiáticos.

No presente artigo interessa-nos perceber de que forma a mídia tem lidado com a questão dos índios. E essa escolha encontra ressonância em nossas pesquisas anteriores que, em sua maior parte, vinculam-se a uma investigação acerca dos sujeitos cujas existências são tidas como aquelas que compõem grupos minoritários sociológicos e que são, no mais das vezes, marginalizados.

Esse esclarecimento sobre o que desperta nosso olhar e afeta nossa pesquisa está vinculado ao que, para os Estudos Culturais, é a tônica: uma reflexão que se revele útil, sendo crítica e engajada, o que significa ser revestida de compromisso político (GRANDI, 1995; JOHNSON, 1999). Ou seja, "la competencia intelectual tiene que convertirse en la función de las luchas, de las clases subordinadas y de los movimientos históricos que las representan"” (JOHNSON, 1999, p. 97).

Localizamos nossas reflexões no campo da comunicação e dos estudos de linguagem. Isso porque os meios de comunicação são produtores de sentidos a partir do momento em que representam a realidade mediante os discursos que propõem. Segundo Escosteguy (2001, p. 67), os media funcionam "dentro e através do domínio discursivo". $\mathrm{E}$, com isso, encontram-se imbricados nas relações de poder. Dentro desse contexto, temos que os meios de comunicação são ideológicos e mais, eles fazem uma leitura da realidade de acordo com os princípios hegemônicos de modo a ser indispensável, para formação de um pensamento crítico, que dominemos o seu funcionamento discursivo.

E, como tal, assumimos a importância de pensar nessa "centralidade que a esfera midiática assume na vida cotidiana e nas relações sociais [e que] vem sendo discutida como uma importante reconfiguração com implicações de diversas ordens, inclusive nas relações de tempo e espaço e nas vivências identitárias" (COGO; BRIGNOL, 2011, p. 76).

Dentre as vivências identitárias, são aquelas relativas às minorias indígenas que nos interessam. Para tanto, tomamos como objeto de análise, duas matérias jornalísticas

\footnotetext{
2 "A competência intelectual tem que se converter em função das lutas, das classes subordinadas e dos movimentos históricos que as representam" (JOHNSON, 1999, p. 97)
} 


\section{Revista InterteXto / ISSN: 1981-0601 \\ v. 10, n. 2 (2017)}

dos portais Nexo e Portal Globo (G1) que veiculam a manifestação dos índios ocorrida no dia 25 de abril de 2017, na Esplanada dos Ministérios. Tais manifestações tiveram como pautas a paralisação na demarcação de terras pelo atual governo, o enfraquecimento das instituições públicas indígenas e as proposições legislativas contrárias aos seus interesses. Foi também motivada pelos recentes assassinatos dos índios, em razão do acirramento dos conflitos com os proprietários de terra especialmente no Mato Grosso do Sul e no Pará.

Uma vez que a mídia é uma

prática discursiva, produto de linguagem e processo histórico, para poder apreender o seu funcionamento é necessário analisar a circulação dos enunciados, as posições de sujeito aí assinaladas, as materialidades que dão corpo aos sentidos e as articulações que esses enunciados estabelecem com a história e a memória (GREGOLIN, 2007, p. 13)

Ou seja, a interação entre os estudos da mídia e os de análise de discurso perfazem o objetivo quanto a compreensão dos sentidos sociais que são produzidos. Os textos midiáticos colocam em circulação esses sentidos e o seu exame se coaduna com a análise de discurso (AD) na medida em que essa se consagra como um "campo de estudo que oferece ferramentas conceituais para a análise desses acontecimentos discursivos" (GREGOLIN, 2007, p. 3).

Assim, nos valemos dos aportes teóricos e metodológicos da análise de discurso, em específico da análise de discurso de linha francesa (ADF), buscando entender, a partir de uma análise das duas matérias selecionadas, quais os sentidos articulados em torno dos índios.

\section{ANÁLISE DE DISCURSO DE LINHA FRANCESA}

Aprendemos com Baccega (1995) que o sujeito se constitui na interação social através da linguagem. Nesse mesmo sentido trazemos Foucault (apud GREGOLIN, 2007) quando o autor afirma que o sujeito, ao falar, já se insere na ordem do discurso. E com Orlandi (2013, p. 15) temos que a "Análise de Discurso concebe a linguagem como mediação necessária entre o homem e a realidade natural e social".

Ou seja, a partir dessas três proposições vislumbramos que não é possível a existência humana sem a linguagem e, consequentemente, sem o discurso. Isso porque "as relações de linguagem são relações de sujeitos e de sentidos e seus efeitos são 


\section{Revista InterteXto / ISSN: 1981-0601}

v. 10, n. 2 (2017)

múltiplos e variados. Daí a definição de discurso: o discurso é efeito de sentidos entre locutores" (ORLANDI, 2013, p. 21).

Consideramos importante iniciar a conceitualização da Análise de Discurso diferenciando-a da Linguística e da Análise de Conteúdo. Quanto à primeira, o objeto que a Análise de Discurso toma para si não é a língua fechada em si - tal como a Linguística o faz - mas o discurso "que é um objeto sócio-histórico em que o linguístico intervém como pressuposto" (ORLANDI, 2013, p. 16).

E ainda, em contraposição aos analistas de conteúdo que buscam encontrar um sentido no texto, aos estudiosos do discurso interessa perceber o modo de significação do mesmo. Nas palavras de Orlandi (2013, p. 17), a Análise de Discurso, considerando a opacidade da linguagem, coloca a questão de "como este texto significa?".

É a partir dos anos 60 que o texto é alçado com qualidade própria de materialidade e significação. Na confluência entre três campos do saber - Linguística, Marxismo e Psicanálise -, a AD toma o discurso como seu objeto próprio de estudo. Dessa forma, incorpora a língua em sua autonomia relativa pois considera sujeito e contexto e, ainda, passa a levar em conta a história e a ideologia.

E se assim o faz não é isentando-se de arguir os três campos com os quais dialoga, ao contrário,

Interroga a Linguística pela historicidade que ela deixa de lado, questiona o materialismo perguntando pelo simbólico e se demarca da Psicanálise pelo modo como, considerando a historicidade, trabalha a ideologia como materialmente relacionada ao inconsciente sem ser absorvido por ele (ORLANDI, 2013, p. 20)

Quanto às origens do que se constitui como Análise de Discurso elencamos duas linhas distintas: a americana e a europeia. Para a primeira, a AD é uma extensão da linguística, ou seja, o que se analisa são os elementos constitutivos do texto. Já para a segunda, ao se analisar um discurso o analista deve necessariamente passar pelo contexto externo, incorporando-o.

Adotamos no presente artigo a corrente europeia, que podemos considerar como sendo de linha francesa. A Análise de Discurso de Linha Francesa (ADF) aprofunda e define o discurso, como visto, para além da linguística, considerando sujeito, contexto, história e ideologia.

Portanto, temos que para a ADF a linguagem não é transparente e reside aí um de seus movimentos importantes: a busca por identificar como cada texto significa. E então, 


\section{Revista InterteXto / ISSN: 1981-0601 \\ v. 10, n. 2 (2017)}

o "que temos, como produto da análise, é a compreensão dos processos de produção de sentido e de constituição dos sujeitos em suas posições" (ORLANDI, 2013, p. 72).

Ou seja, a composição entre a linguagem, o social, o histórico e a ideologia, garantem um lugar de fala ao sujeito, a ser desvelado pela Análise de Discurso, tanto nos sentidos produzidos, quanto nos lugares ocupados, como nos faz perceber Orlandi (2013). E é importante destacarmos que no Brasil a introdução da ADF sobrevém no final da década de 70 com a pesquisadora Eni Orlandi (FERREIRA, 2007). Ao longo desses quase cinquenta anos os autores brasileiros já consolidaram os instrumentais teóricos necessários para a realização da análise de um discurso (FERREIRA, 2007; ORLANDI, 2013).

Porém, ainda que existam dispositivos teóricos à mão, a ADF torna inconteste para o analista o seu papel: apreender o que advém do texto, a partir dos filtros que a cada um, e de maneiras diferentes, perpassam. Ou seja, consiste em deixar o texto contar o modo como a análise será realizada.

\section{3. ÍNDIOS, UM APAGAMENTO VIOLENTO}

As reflexões de Orlandi (2008) são importantes para que possamos compreender o apagamento promovido pelo Estado brasileiro branco que no exercício de sua hegemonia retira a cultura dos índios como parte integrante da sua identidade nacional, silenciandoos em um duplo aspecto: tanto a respeito de quem são quanto do que fazem.

Para a autora esse apagamento do índio da identidade cultural do Brasil vem sendo consolidado há tempos "e se produz pelos mecanismos mais variados, dos quais a linguagem, com a violência simbólica que ela representa, é um dos mais eficazes" (ORLANDI, 2008, p. 66). Ela elenca três campos em que as construções discursivas preponderam para tornar o índio objeto desse esvaziamento, quais sejam, a religião, a ciência e a política social.

Orlandi (2008) coloca que tais discursos encampam diretrizes liberais e confluem para um mesmo norte: aquele que iguala juridicamente os índios, como cidadãos cumpridores de deveres e sujeitos de direitos. Uma implicação daí decorrente é que 


\section{Revista InterteXto / ISSN: 1981-0601 \\ v. 10, n. 2 (2017)}

quais o índio passa a ser visto pelas qualidades que não são suas (ORLANDI, 2008, p. 68)

Há uma lógica etnocêntrica que permeia a relação do Estado branco para com os índios pois ao mesmo tempo em que não se reconhece o índio a partir das suas características e cultura, objetiva-se aniquilá-lo na qualidade desse "outro", fazendo prevalecer a cultura e os valores do sujeito branco e não índio. Podemos vislumbrar essa lógica em todos os acontecimentos que dizem respeito aos índios, em suas dificuldades para se firmarem como sujeitos com existências a serem reconhecidas, respeitadas e dignificadas.

Segundo nos faz perceber Orlandi, esse apagamento

é do domínio da ideologia. Não está marcado em lugar nenhum como tal. Funciona através dos silêncios, de práticas que o atestam, mas que não se expõem como tal. Daí sua eficácia. É claro que esse silêncio, uma vez estabelecido, volta sobre o mundo com toda a sua violência. Dessa forma, do apagamento ideológico se passa para o extermínio, que tem, por sua vez, formas mais ou menos diretas de violência: desde o assassinato puro e simples até a exclusão do índio da discussão de problemas que o afetam diretamente (ORLANDI, 2008, p. 69)

As duas matérias selecionadas evidenciam todas essas formas de violência. Os acontecimentos já são, em si, avassaladores frente a dignidade dos índios - genocídio, perseguições, falta de reconhecimento de legitimidade de sua etnia, ausência de demarcação de suas terras - e a mídia ainda reforça o pior dos acontecimentos, pela forma como constrói suas narrativas em torno dos fatos noticiados.

Em síntese a matéria $O$ que é ser indígena no Brasil hoje, segundo 3 jovens e 2 antropólogos $(\mathrm{NexO})^{3}$, datada de 29 de abri, e de autoria de José Orenstein, discorre brevemente sobre a manifestação ocorrida quatro dias antes, fornecendo um panorama das reivindicações dos índios. Todavia o foco majoritário da reportagem está em discutir a garantia de direitos e debater a identidade indígena, conferindo a palavra para três jovens indígenas e dois antropólogos. Já a notícia Índios fecham Esplanada e entram em conflito com PM em ato por demarcação (Portal G1) ${ }^{4}$ foi publicada no dia da manifestação, sem autoria definida. Noticiou a manifestação dos índios e a ação da polícia.

Disponível em: https://www.nexojornal.com.br/expresso/2017/04/29/O-que-é-ser-ind\%C3\%ADgena-no-Brasil-hoje-segundo-3-jovens-e-2antropólogos?utm campaign=a nexo 20170502\&utm medium=email\&utm source=RD+Station Acesso em jun. 2017

${ }^{4}$ Disponível em: http://gl.globo.com/distrito-federal/noticia/indios-fazem-manifestacao-em-brasilia-e-fecham-esplanada-houveconfronto-com-pm.ghtml Acesso em jun. 2017 


\section{Revista InterteXto / ISSN: 1981-0601 \\ v. 10, n. 2 (2017)}

Sabemos que na contemporaneidade os meios de comunicação desempenham um papel relevante. Tanto é que ao atuarem muitas vezes como substitutos dos velhos agentes (partidos, igrejas, sindicatos), se constituem como agências socializadoras e passam a reestruturar o público e o privado (CANCLINI, 2008). Inclusive podemos afirmar que o papel preponderante que desempenham é ressaltado ainda mais na medida em que propõem novos modos de ser, pensar e agir.

E é através das narrativas - chamadas de midiáticas -, que os meios de comunicação propõem seus significados. Ou seja, a produção de sentidos se dá através do domínio discursivo mediante a articulação de elementos sociais e simbólicos.

Uma vez que "a inclinação dos media é reproduzir o campo ideológico da sociedade em tal forma que reproduz, também, sua estrutura de dominação" (ESCOSTEGUY, 2001, p. 71), é nosso dever constatar que a proposição de sentidos pelos meios de comunicação não se dá de maneira isenta. Ao contrário, resgatamos Kellner que traz a necessidade de lermos o que ele denomina como cultura da mídia:

Isso significa não só ler essa cultura no seu contexto sociopolítico e econômico, mas também ver de que modo os componentes internos de seus textos codificam relações de poder e dominação, servindo para promover os interesses dos grupos dominantes à custa de outros, para opor-se às ideologias, instituições e práticas hegemônicas, ou para conter uma mistura contraditória de formas que promovem dominação e resistência (KELLNER, 2001, p. 76)

Para Baccega (2003) a realidade que apreendemos a partir dos meios de comunicação é editada e somente destrinchando o funcionamento dos mesmos é que podemos conhecer o mundo desvelado - tal como ele é - de modo a então agirmos sobre ele. No mesmo sentido nos aponta Gregolin:

A criação dessa ilusão de 'unidade' do sentido é um recurso discursivo que fica evidente nos textos da mídia. Como o próprio nome parece indicar, as mídias desempenham o papel de mediação entre seus leitores e a realidade. $O$ que os textos da mídia oferecem não é a realidade, mas uma construção que permite ao leitor produzir formas simbólicas de representação da sua relação com a realidade concreta (GREGOLIN, 2007, p. 16)

Portanto, quando falamos em criticidade, estamos a tratar de um processo indissociável entre uma imperiosa contextualização de determinado texto midiático e a apreensão de seus sentidos na contramão da intenção que possa vir subjacente, no sentido de preservar o status quo dominante. Nesse sentido torna-se relevante examinar 


\section{Revista InterteXto / ISSN: 1981-0601}

v. 10, n. 2 (2017)

as matérias do Nexo e do Portal Globo (G1) à luz de alguns conceitos que compõem a ADF.

\section{ANÁLISE: UMA BREVE INTRODUÇÃO}

As matérias selecionadas têm uma abordagem diferente para com o fato noticiado, compatíveis com a forma como cada veiculo elabora as suas narrativas. O Nexo é um jornal digital e se volta para um público composto por leitores que desejam "informações contextualizadas, com uma abordagem original” ${ }^{5}$. É mais recente e tem uma abrangência menor. Já o Portal G1 existe desde 2006, podendo ser qualificado como de maior abrangência. É mantido pela Globo.com, sob orientação da Central Globo de Jornalismo, que é o maior conglomerado midiático latino-americano.

Para termos uma noção em termos quantitativos da abrangência desses veículos juntos aos leitores, utilizamos como critério o engajamento dos internautas frente ao Facebook, mediante o que podemos observar a maior interação para com o Portal G1: a página do Nexo no Facebook tem 312.208 mil curtidas e 313.061 mil seguidores enquanto que a do Portal G1 tem 9.496.203 milhões de curtidas e 9.380.522 milhões de seguidores.

Selecionamos as duas matérias por interessar perceber não só os sentidos articulados em torno do índio - no que diz respeito à manifestação ocorrida em Brasília no dia 25 de abril de 2017 - mas a localização desses sentidos em diferentes perspectivas. E essa diferença é marcada pela forma como cada veículo noticia o fato.

Após a leitura de cada matéria, optamos por analisá-las separadamente, devido às diferenças que observamos no modo de construir a notícia por parte de cada veículo. Para cada uma, portanto, elegemos uma categoria empírica, a fim de auxiliar nossa escuta discursiva. Por meio dessas categorias - dispositivos analíticos - acreditamos ser possível pensar como tais textos significam o índio.

\subsection{0 conflito}

\footnotetext{
${ }^{5}$ Disponível em https://www.nexojornal.com.br/about/Sobre-o-Nexo Acesso em jun. 17
} 


\section{Revista InterteXto / ISSN: 1981-0601}

v. 10, n. 2 (2017)

No caso do Portal G1, em sua matéria intitulada Índios fecham Esplanada e entram em conflito com PM em ato por demarcação, escrita no dia da manifestação, a narrativa tem um foco: o conflito. Todos os elementos discursivos confluem para essa percepção, inclusive os comentários dos leitores da página que colocam o índio como um "outro" que causa perturbação e é passível de ser aniquilado. De modo que optamos por assumir conflito como nossa categoria de análise empírica para o Portal G1.

O próprio subtítulo da notícia deixa antever tal construção: Grupo ocupou espelho d'água do Congresso, e PM reagiu com bombas, spray e balas de borracha. Indígenas revidaram com flechas, e quatro foram detidos; veja vídeos. A composição entre a linguagem verbal, as imagens e os vídeos, conduz a percepção do leitor para uma situação de caos. E, como podemos perceber nos comentários deixados na matéria, essa é também a percepção dos leitores:

Imagem 1: comentários Portal G1

indios de iphone....que pais é esse...bando de faz nada... 27 | 12

\section{Não farão falta.}

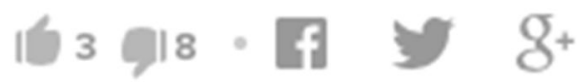

Tudo por culpa dos portugueses, que não terminaram o serviço.

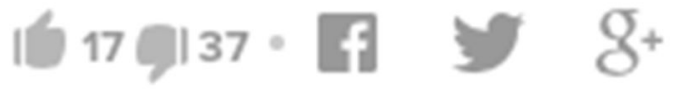

\section{HÁ 2 MESES}

Índios são bandidos com alforria para cometer crimes. Morte aos índios já!!

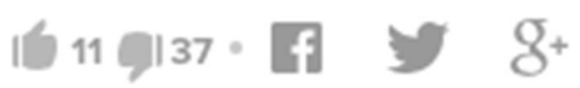

Fonte: Portal G1 ${ }^{6}$

\footnotetext{
6 Disponivel em http://gl.globo.com/distrito-federal/noticia/indios-fazem-manifestacao-em-brasilia-e-fecham-esplanada-houveconfronto-com-pm.ghtml Acesso em jun. 2017
} 


\section{Revista InterteXto / ISSN: 1981-0601 \\ v. 10, n. 2 (2017)}

Quando, mediante a ADF, atentamos para as condições de produção do discurso, percebemos a ressonância entre esses comentários de ódio e o modo como a narrativa da matéria está organizada. Lembrando que "a noção de condições de produção pode ser definida como o conjunto dos elementos que cerca a produção de um discurso" (BRANDÃO, 2015, p. 22), Detemos nossa atenção especialmente na formação imaginária, a partir da qual emerge o conceito de relação de sentidos. Interessa, portanto, perceber o apontamento de sentidos entre discursos. É dessa maneira que podemos considerar todo discurso "como um estado de um processo discursivo mais amplo" (ORLANDI, 2013, p. 39).

No caso em exame, a partir do momento em que a matéria não explica sobre a realidade dos índios, não informa quem são e os motivos que ensejam sua manifestação, estabelece uma relação com aqueles sentidos provenientes de um discurso nacional que visa o aniquilamento dos índios, retirando-Ihes suas legítimas existências e demandas. Há uma completa ausência de informações na matéria, que seriam essenciais para o entendimento das identidades dos índios bem como dos motivos que dão ensejo às suas lutas e reivindicações.

E acreditamos que a notícia, ao não articular nada sobre os índios e, ainda, ao construir uma narrativa calcada no conflito, abre espaço para a condução do leitor em direção à univocidade de sentidos que constroem os índios como bandidos, desnecessários, merecedores do aniquilamento, preguiçosos, não sujeitos (imagem 1). De acordo com Orlandi (2008, p. 69) esse apagamento é pressuposto da consciência nacional na medida em que "qualquer discurso que se refira à identidade da cultura nacional já tem inscrita a exclusão do índio, necessariamente, como um princípio".

Os discursos da notícia do G1 bem como, dos comentários de ódio, se apropriam de uma visão estereotipada de realidade, construída sobre juízos prévios, baseada em juízos de valor. É por meio dessa realidade que o $G 1$ transmite informações sobre as manifestações e que os leitores expressam suas opiniões sobre os índios. Ambos partem, em nosso entender, de uma realidade maculada - posto que provinda de um arraigado apagamento - acerca de quem são os índios.

Outro aspecto que consideramos relevante observar diz respeito à ideologia. Com Baccega (1995, p. 49) lançamos o alerta quanto à força ideológica das conclusões dos leitores sobre os índios pois "na palavra está a manifestação do sistema de valores, da ideologia, constituída e em constituição". Retomamos em Bakhtin (2013) o caráter de 


\title{
Revista InterteXto / ISSN: 1981-0601 \\ v. 10, n. 2 (2017)
}

arena do signo ideológico: é nele que se confrontam índices de valor contraditórios. E a naturalização de um sentido tem lugar quando da concretização de uma ideologia dominante no seio social que determina uma significação única.

Persevera nos leitores do Portal G1, como se percebe, a ideologia do homem branco que não se importa com a existência do índio mas ao contrário, deseja a sua exclusão e o seu apagamento. Ideologia que tem por esteio um discurso sobre o índio que reduz sua existência à três esferas: religiosa, política social e científica sendo dessa forma que o índio

\begin{abstract}
Existe enfaticamente no discurso do missionário, do antropólogo e no do indigenista e deixa de existir na 'consciência nacional', isto é, deixa de existir na própria constituição da nacionalidade. Diríamos, pois, que esse discurso que coloca o índio como objeto de observação, paradoxalmente, resulta na produção de sua invisibilidade. A tematização do índio nesses discursos funciona como indício de seu apagamento (ORLANDI, 2008, p. 69)
\end{abstract}

A notícia do Portal G1, apesar de extensa, enuncia apenas duas informações pontuais e sintéticas sobre as reivindicações dos índios que se resumem nos seguintes trechos: (i) O grupo protesta contra o governo Temer e reivindica o avanço na demarcação de terras indígenas; e (ii) noticiam que os índios participam em Brasília da $14^{\mathrm{a}}$ edição Acampamento Terra Livre cujo objetivo é pedir mais respeito à natureza e à demarcação de terras.

Ou seja, a matéria constrói uma pormenorizada narrativa em torno, apenas, das ações do ato - e não sobre os sentidos das reivindicações dos índios -, colocando-os como aqueles que afrontam uma pretensa ordem ao ingressarem no Congresso Nacional e a Tropa de Choque como a mantenedora da paz social. A matéria não questiona o emprego da violência por parte da polícia que usou bombas de gás, balas de borracha e spray de pimenta apenas reforçando, por meio de vídeo, que os policiais fugiram dos índios armados com flechas e, por meio de textos, que os policiais apreenderam 50 flechas em confronto com índios em Brasília. Vislumbramos, portanto, o Estado Brasileiro em uma posição passiva - ainda que tenha partido de um de seus braços armados (polícia) a incitação para o confronto - enquanto que aos índios cabe a posição ativa, como aquela que perturba a ordem. 


\section{Revista InterteXto / ISSN: 1981-0601 \\ v. 10, n. 2 (2017)}

\subsection{A ocultação}

Em linhas gerais o Nexo apresenta um contraponto ao que observamos na matéria do G1. O título já mostra que a narrativa irá partir do fato - manifestação - para articular sobre os índios. Essa intenção fica evidente na forma como a matéria se organiza: uma breve descrição acerca do contexto da manifestação, e de seu mérito; uma lista com quatro pontos que preocupam os índios (suspensão das demarcações; sucateamento da Funai; proposições legislativas contrárias aos seus interesses; e tese do Marco Temporal); informações complementares acerca da situação contemporânea dos índios, com dados sobre quem são e sobre o que dificulta dizer sobre suas identidades: "as culturas das 305 etnias indígenas do Brasil, que perfazem uma população de mais de 800 mil pessoas, são muito diversas e, ao longo do tempo, incorporaram elementos de culturas não indígenas, o que gera questionamentos sobre o que é ser índio" (ORNESTEIN, 2017).

A partir daí são lançadas duas perguntas: o que é ser indígena no Brasil hoje? voltada para três índias e por que o senso comum nega aos indígenas sua identidade quando eles incorporam hábitos e tecnologias não indígenas ao seu dia a dia? direcionadas a dois antropólogos. Esta última pergunta esboça uma reflexão acerca do comentário do leitor da matéria do $G 1$ "índios de iphone...que país é esse...bando de faz nada" (imagem 1).

Após uma leitura atenta da matéria delimitamos como categoria possível de análise a ocultação. O verbo ocultar tem seu significado definido pelo dicionário Michaelis como encobrir, esconder. Entendemos que ao mesmo tempo em que a notícia está empenhada em trazer informações sobre os índios, o faz mediante o ocultamento da voz desse próprio índio.

De antemão verificamos essa ambiguidade no título da reportagem. É nítido o propósito do Nexo de debater e refletir sobre a condição/situação do índio, porém desde logo não menciona índia(o) quando se refere (às)aos jovens - só mais tarde veremos tratarem-se de as jovens -, e além disso, confere às mesmas um reduzido espaço na matéria. De modo que o título $O$ que é ser indígena no Brasil hoje, segundo 3 jovens e 2 antropólogos está na contramão da visibilidade que o veículo pretende conferir à questão indígena, apagando o fato de que são jovens e que são índias. Percebemos também uma acentuada inviabilização de gênero atrelada na omissão do título. 


\section{Revista InterteXto / ISSN: 1981-0601 \\ v. 10, n. 2 (2017)}

E observamos, ainda, o pouco espaço para a fala das próprias índias no corpo da notícia. À elas, Giselda Pires de Lima (Guarani), Nelly Duarte (Marubo) e Ysani Kalapalo (Awati e Kalapalo) são conferidos três pequenos trechos, com letra de maior tamanho, o que diminui a extensão do conteúdo do texto. Ou seja, a narrativa do Nexo tem fluência e coerência enquanto está apresentando e examinando os fatos sob diferentes aspectos incluindo aí as perspectivas provindas dos índios - porém de certo modo reproduz, em seu título e na sua forma de composição, a estrutura e a fala dominante do homem branco sobre o índio. Percebemos, com isso, que há um resquício do apagamento do índio, não explicitamente pontuado porém reflexamente expressado.

Complementamos com Orlandi (2008) quando a autora ressalta à quais esferas discursivas encontram-se confinados os índios no Brasil - religião, ciência e política social. Na matéria do Nexo destaca-se o papel da ciência na fala, principalmente, dos antropólogos. Eles são chamados a dizer sobre a identidade indígena, seus limites e contornos (incluída a questão da incorporação de tecnologias).

Em contrapartida, às três índias, foi direcionada somente uma questão e de cunho mais generalista: o que é ser indígena no Brasil hoje? Tal indagação atravessa as outras duas, dirigidas aos antropólogos, porém notamos que a matéria acaba por conferir maior poder de dizer sobre os índios aos homens brancos, e não às/aos índias(os).

Se a partir da compreensão das formações discursivas apreendemos que "o sentido não existe em si mas é determinado pelas posições ideológicas colocadas em jogo no processo sócio-histórico em que as palavras são produzidas" (ORLANDI, 2013, p. 42), constatamos que nesse caso em específico a mídia contribui para o silenciamento da voz do índio vez que opta por dizer sobre quando poderia ter escutado - em igual ou em maior proporção - a própria voz do índio. Não importa identificar o mérito de tal opção da reportagem do Nexo, a partir de orientações de produção, pauta, diretriz editorial. Qualquer fundamento que justifique formatar a matéria com a preponderância para a voz dos antropólogos, passa pela questão de fundo a que chamamos atenção que é a da perpetuação do apagamento do índio da consciência nacional, que transparece na maior parte dos discursos sobre os índios.

\section{APONTAMENTOS CONCLUSIVOS}




\section{Revista InterteXto / ISSN: 1981-0601 \\ v. 10, n. 2 (2017)}

No presente artigo, analisamos os sentidos articulados em torno dos índios pelos enunciados midiáticos de Nexo e Portal G1, tendo como ponto de início as manifestações de abril desse ano, em decorrência dos recentes assassinatos de líderes indígenas em conflitos por terra, e, também, das iniciativas contrárias à dignidade dos índios, que vêm sendo perpetradas nos âmbitos dos poderes executivo e legislativo.

O exame acerca das condições de produção das matéria do Portal G1 e do Nexo resultou na percepção quanto à ressonância dos discursos midiáticos ao apagamento dos índios, praticado pelo Estado brasileiro ao longo do tempo. Identificamos uma formação discursiva com raízes arraigadas em uma formação ideológica colonialista, aquela que traz uma relação de poder calcada em uma autoridade que se apropria, explora e dizima, no que concerne ao G1 e um apagamento da voz do índio, no que diz respeito ao Nexo. Evidenciou-se, portanto, uma extinção física e outra simbólica.

Sabemos que "uma mesma palavra pode ter sentidos diferentes de acordo com a formação discursiva e ideológica em que se inscreve" (BRANDÃO, 2015, p. 23) o que traz a necessidade de estarmos atentos quanto "ao jogo polissêmico que mascara sob a aparência do mesmo o outro sentido, ou os sentidos indesejados" (Idem). Notamos que a matéria do G1 tem o seu foco articulado no conflito e que desloca os sentidos que constrói em torno do índio para a univocidade que pretende que é a de atribuir-lhe a autoria desse conflito.

A imagem desse índio informada pelo G1 é ressignificada pelos leitores, para quem os índios são bandidos, desnecessários, merecedores do aniquilamento, preguiçosos, não sujeitos (imagem 1). Se para a língua não importa a posição dos sujeitos, nem tampouco a ideologia, ao discurso tais elementos são cruciais pois "o falante utiliza a língua de acordo com a sua posição social e ideológica" (BRANDÃO, 2015, p. 26).

Os leitores encontram-se em um determinado contexto sócio-histórico - ou seja, são marcados pela historicidade - e expressam a partir daí, os seus comentários. Neles identificamos discursos de ódio, provindos de sujeitos brancos, interpelados pela ideologia colonialista, por valores e crenças de quem já explorou e a quem interessa o extermínio dos índios.

Em contrapartida, a matéria do Nexo trouxe as informações que faltaram ao G1. A evidência do propósito do veículo em informar acerca de quem são e pelo que lutam os índios fica clara, do começo ao fim da notícia. Assim vislumbramos, sob a ótica do dialogismo, os discursos midiáticos do Nexo em direção oposta ao do G1. O que, a partir 


\section{Revista InterteXto / ISSN: 1981-0601 \\ v. 10, n. 2 (2017)}

das análises, permite-nos apreender a historicidade nesse "movimento dialético de constituição do sentido" (FIORIN, 2015, p. 66) em torno dos índios.

Todavia, a matéria do Nexo reflete, ainda que não intencionalmente, a prática discursiva predominante na mídia brasileira, arraigada em uma concepção colonialista, de silenciamento dos índios. Como observamos, desde o título da notícia até o espaço concedido aos cientistas e, em tamanho reduzido às três jovens índias, confluem para uma prática discursiva que toma como predominante a enunciação do antropólogo que fala sobre os índios ao invés de escutar os índios.

\section{Referências}

BACCEGA, M. A. Palavra e discurso: história e literatura. SP: Ática, 1995.

Narrativa ficcional de televisão: encontro com os temas sociais. Comunicação \& Educação, Brasil, n. 26, p. 7-16, jan/abr. 2003.

BAKTHIN, M. M. Marxismo e filosofia da linguagem: problemas fundamentais do método sociológico da linguagem. São Paulo: Hucitec, 2014.

BARBOSA, P. L. N. O papel da imagem e da memória na escrita jornalística da história do tempo presente. In: GREGOLNI, M. R. (org.). Discurso e mídia: a cultura do espetáculo. São Carlos: Claraluz, 2003.

BRANDÃO, H. N. Enunciação e construção do sentido. In: FÍGARO, R. (org.). Comunicação e Análise do Discurso. São Paulo: Contexto, 2015.

CANCLINI, Néstor Garcia. Consumidores e cidadãos: conflitos multiculturais da globalização. p. 11-73. Rio de Janeiro: Editora UFRJ, 2008.

COGO, D.; BRIGNOL, L. D. Redes sociais e os estudos de recepção na internet.

MATRIZES, ano 4, n. 2, jan./jun. 2011, São Paulo, p. 75-92, 2011.

ESCOSTEGUY, A. C. Cartografias dos Estudos Culturais: uma versão latino-americana. Belo Horizonte: Autêntica, 2001.

FERRERIA, M. C. L. Análise do Discurso no Brasil: notas à sua história. In: Fernandes, C. A.; Santos, J. B. C (orgs.). Percursos da Análise do Discurso no Brasil. São Paulo: Editora Claraluz, 2007.

FIORIN, J. L. Enunciação e comunicação. In: FÍGARO, R. (org.). Comunicação e Análise do Discurso. São Paulo: Contexto, 2015. 


\section{Revista InterteXto / ISSN: 1981-0601 \\ v. 10, n. 2 (2017)}

GRANDI, R. Los estudios culturales: entre texto y contexto, culturas e identidade. In: GRANDI, R. Texto y contexto en los medios de comunicación, Bracelona: Bosch, 1995, p. 93-116.

GREGOLIN, M. R. Análise do discurso e mídia: a (re) produção de identidades. In: Comunicação, Mídia e Consumo. vol. 4, n. 11, p. 11-25, 2007.

JOHNSON, R. O que é afinal estudos culturais? In: JOHNSON, R. ESCOSTEGUY, A. C.; SCHULMAN, N. O que é, afinal, estudos culturais? Belo Horizonte: Autêntica, 1999, p. 7131.

KELLNER, Douglas. A cultura da Mídia - estudos culturais: identidade e política entre o moderno e o pós-moderno. p. 9-43. São Paulo: EDUSC, 2001.

LONARDONI, M. O discurso da ascensão, auge e queda de Antonio Palocci, na ótica das capas de Veja. In: NAVARRO, P. (org.). Estudos do texto e do discurso: mapeando conceitos e métodos. São Carlos: Claraluz, 2006.

ORLANDI, E. Terra à vista - Discurso do confronto: velho e novo mundo. $2^{\mathrm{a}}$ ed. Campinas, SP: Editora da Unicamp, 2008.

ORLANDI, E. Análise de Discurso: princípios e procedimentos. Campinas: Pontes, 2013.

SCHAFF, A. Lenguaje y acción humana. In: SCHAFF, Adam. Ensayosm sobre filosofia del lenguaje. Barcelona: Ariel, 1973. p. 124-145.

Artigo recebido em julho de 2017.

Artigo aceito em abril de 2018. 